\title{
Exponential Fed-Batch Cultures of Klebsiella pneumoniae under Anaerobiosis Using Raw Glycerol as a Substrate to Obtain Value-Added Bioproducts
}

\author{
Allan Morcelli, ${ }^{a}$ Rosane Rech, ${ }^{a}$ Andre Klafke, ${ }^{a}$ Rafael Pelegrini ${ }^{b}$ and Marco A. Z. Ayub ${ }^{*, a}$ \\ ${ }^{a}$ Grupo de Biotecnologia, Bioprocessos e Biocatálise, Instituto de Ciência e Tecnologia de Alimentos (ICTA), \\ Universidade Federal do Rio Grande do Sul (UFRGS), Av. Bento Gonçalves, 9500, \\ CP 15095, 91501-970 Porto Alegre-RS, Brazil \\ ${ }^{b}$ Departamento de Engenharia Química, Universidade Federal do Rio Grande do Sul (UFRGS), \\ Av. Bento Gonçalves, 9500, CP 15090, 91501-970 Porto Alegre-RS, Brazil
}

\begin{abstract}
In this study, Klebsiella pneumoniae BLh-1 was grown under exponential fed-batch mode in cultures using raw glycerol from biodiesel synthesis under anaerobiosis to produce value-added products. Specific growth rates of $0.035,0.07$, and $0.105 \mathrm{~h}^{-1}$ were tested and 1,3-propanediol (1,3-PDO) and ethanol were produced in all cultures, whereas the formation of 2,3-butanediol was not observed. The highest concentrations of 1,3-PDO (38.5 $\left.\mathrm{g} \mathrm{L}^{-1}\right)$ and ethanol $\left(13.2 \mathrm{~g} \mathrm{~L}^{-1}\right)$ were achieved under the specific growth rate of $0.105 \mathrm{~h}^{-1}$. Acetic and lactic acids were also produced at high concentrations (17.3 and $7.8 \mathrm{~g} \mathrm{~L}^{-1}$, respectively) under these conditions. The yields of 1,3-PDO and ethanol increased over time, reaching final values of 0.56 and $0.19 \mathrm{~g} \mathrm{~g}^{-1}$, respectively. Overall productivities were $1.43 \mathrm{~g} \mathrm{~L}^{-1} \mathrm{~h}^{-1}$ for $1,3-\mathrm{PDO}$ and $0.49 \mathrm{~g} \mathrm{~L}^{-1} \mathrm{~h}^{-1}$ for ethanol. Compared to batch results, fed-batch operation favored $K$. pneumoniae metabolism towards the production of 1,3-PDO and ethanol, being an interesting process to add value to the ever-growing availability of raw glycerol from biodiesel industry.
\end{abstract}

Keywords: biodiesel raw glycerol, Klebsiella pneumoniae, 1,3-propanediol, ethanol, fedbatch cultivations

\section{Introduction}

Biodiesel production has increased over the last years, which has been stimulated by the environmental benefits of its productive system, since it is a process that uses renewable biological resources. ${ }^{1}$ The constant search for energy independence from fossil fuels promotes biodiesel as an important alternative fuel, and ranking among its advantages are the rural development and the reduction of greenhouse gases emissions. ${ }^{2}$ Because of the growing production of biodiesel, there has been exceeding availability of glycerol, the main by-product of this industry. ${ }^{3}$ The proper handling of raw (or residual) glycerol, especially in biorefineries, would benefit the overall costefficiency of biodiesel production by reducing waste disposal costs and, more importantly, by its conversion into value-added chemicals. ${ }^{4}$ Raw glycerol purification is costly, and the current global market of this commodity is saturated, which causes reduced prices. This effect should

*e-mail: mazayub@ufrgs.br persist as more biodiesel manufacturing facilities start up. The use of low-grade glycerol derived from biodiesel production is becoming a huge challenge since it cannot be used for food or cosmetic purposes without further purification. $^{5}$

One possible industrial alternative for the use of raw glycerol is its use in microbiological processes as a substrate in fermentation to obtain several metabolites of interest. The bioconversion of glycerol by microorganisms generally shows high selectivity and efficiency and short reaction times. ${ }^{6}$ Among microorganisms able to metabolize glycerol into products of industrial interest, Klebsiella pneumoniae has received considerable attention. This bacterium is a facultative anaerobic, metabolically versatile microorganism, which has been investigated in the production of 1,3-propanediol (1,3-PDO), 2,3-butanediol (2,3-BDO), ethanol, and several organic acids. ${ }^{7}$ Among such metabolites, 1,3-PDO, 2,3-BDO, and ethanol are of special interest. On the other hand, the formation of acetic acid and lactic acid in the fermentation process is undesirable, since they are known inhibitory metabolites 
and will lead to lower yields of the main fermentation products. $^{8}$

1,3-PDO is a polyol that has a wide range of applications, including cosmetics, foods, lubricants, and the pharmacological industry. ${ }^{9}$ The development of polytrimethylene terephthalate (PTT) has created a renewed demand for 1,3-PDO. PTT is a thermoplastic that exhibits physicochemical properties that are superior to polyethylene terephthalate (PET), e.g., higher resistance to dirt and staining than PET and polybutylene terephthalate (PBT), and is widely used in the production of fabrics, carpets, and plastics. ${ }^{10}$ The possibility that process improvements in the biological routes could enable the production of 1,3-PDO with the economy required by these competitive markets has fueled large efforts in this field. Biological efforts, which are widely considered as cleaner alternatives over chemical processes, include fermentation optimization of the natural glycerol-utilizing process and metabolic engineering efforts to build a single microorganism capable of utilizing $D$-glucose. The latter development resulted in a cost-competitive biological process by DuPont ${ }^{\mathrm{TM}} .^{11}$ Nevertheless, raw glycerol is an abundant industrial waste and its use as substrate in the production of 1,3-PDO would avoid competition for feedstock between food and chemical industries. Currently, the biggest constraints are low yields and productivities, primarily because bioprocesses are carried out at physiological temperature, atmospheric pressure and mostly in batch operation mode. Process optimization along with fed-batch and continuous operation modes could overcome these constraints. ${ }^{12}$

The use of a fed-batch strategy allows for the regulation of microorganism physiology through the maintenance of substrate concentration at desired levels, since cells can grow exponentially during the entire culture period if the feed rate of the growth-limiting substrate is increased proportionally to cell growth. ${ }^{13}$ It may keep inhibitory products at lower concentrations as well as direct metabolic flux towards the production of desired products. Efforts towards the fed-batch production of 1,3-PDO from glycerol have been concentrated in continuous or batch-pulsed feeding, as well as linked to $\mathrm{pH}$ control, ${ }^{7,14-21}$ and have generally resulted in higher titers, yields and productivities, compared to batch fermentation. However, exponential fedbatch cultures (EFBC) have not been reported. Exponential feeding is a simple method that allows cells to grow at a constant growth rate. It is a simple open-loop control strategy. ${ }^{22}$ Based on these considerations, this work aimed at evaluating the effects of using EFBC of $K$. pneumoniae BLh-1 under anaerobiosis on the pool of metabolites produced by this bacterium. Therefore, fed-batch cultures were carried out through controlled addition of glycerol as culture substrate based on an exponential feeding profile $\mathrm{F}(\mathrm{t})$, which was generated from theoretical cell growth and substrate consumption equations.

\section{Experimental}

\section{Raw glycerol}

The raw glycerol (also called residual glycerol in the literature) used in this work was provided by a biodiesel facility located in Canoas, Rio Grande do Sul, Brazil. Its composition consisted of (in a mass basis) $82.97 \%$ glycerol, $10.62 \%$ moisture, $5.72 \% \mathrm{NaCl}, 0.75 \%$ monoglycerides (MONGs), and trace-concentration of ash and residual methanol. Biodiesel in this plant is produced by transesterification of soybean oil using methanol as the alcohol.

Microorganism maintenance and inoculum preparation

K. pneumoniae BLh-1 was isolated and characterized in the work of Rossi et al. ${ }^{7}$ Certified stocks of this bacterium are kept at the Microbiology Culture Collection of BiotecLab (Universidade Federal do Rio Grande do Sul (UFRGS), Porto Alegre, Rio Grande do Sul, Brazil). Cultures were maintained on a Luria-Bertani agar slant at $4{ }^{\circ} \mathrm{C}$, and new subcultures were started every 4 weeks. The medium for inoculum preparation had the following composition: $5 \mathrm{~g} \mathrm{~L}^{-1}$ yeast extract, $5 \mathrm{~g} \mathrm{~L}^{-1}$ peptone, $7 \mathrm{~g} \mathrm{~L}^{-1}$ $\left(\mathrm{NH}_{4}\right)_{2} \mathrm{SO}_{4}, 7 \mathrm{~g} \mathrm{~L}^{-1} \mathrm{~K}_{2} \mathrm{HPO}_{4}, 1 \mathrm{~mL}$ trace elements solution (containing $0.1 \mathrm{~g} \mathrm{~L}^{-1} \mathrm{MnCl}_{2} \cdot 4 \mathrm{H}_{2} \mathrm{O}, 0.06 \mathrm{~g} \mathrm{~L}^{-1} \mathrm{H}_{3} \mathrm{BO}_{3}$, $0.0037 \mathrm{~g} \mathrm{~L}^{-1} \mathrm{CuSO}_{4} \cdot 5 \mathrm{H}_{2} \mathrm{O}, 0.2 \mathrm{~g} \mathrm{~L}^{-1} \mathrm{CoCl}_{2} \cdot 6 \mathrm{H}_{2} \mathrm{O}, 0.025 \mathrm{~g} \mathrm{~L}^{-1}$ $\mathrm{NiCl}_{2} \cdot 6 \mathrm{H}_{2} \mathrm{O}, 0.035 \mathrm{~g} \mathrm{~L}^{-1} \mathrm{Na}_{2} \mathrm{MoO}_{4} \cdot 2 \mathrm{H}_{2} \mathrm{O}, 0.14 \mathrm{~g} \mathrm{~L}^{-1}$ $\mathrm{ZnSO}_{4} \cdot 7 \mathrm{H}_{2} \mathrm{O}$, and $0.9 \mathrm{~mL} \mathrm{HCl} 37 \%$ ), and $65 \mathrm{~g} \mathrm{~L}^{-1}$ raw glycerol. The inocula were prepared by transferring one loopful of cells into $500 \mathrm{~mL}$ flasks filled with $200 \mathrm{~mL}$ of this medium and then incubated at $37{ }^{\circ} \mathrm{C}$ in a rotatory shaker that operated at $150 \mathrm{rpm}$ for $12 \mathrm{~h}$. Subcultures were incubated under these same conditions, allowing for growth until an optical density (OD) of 1.0 at $600 \mathrm{~nm}$.

\section{Batch cultivations}

Batch experiments were performed in 2-L stirredtank bioreactors (Biostat B model, B. Braun Biotech International, Germany), equipped with $\mathrm{pH}$, temperature, agitation (two flat six-blade turbines), airflow, and chemical-flow controls. Anaerobic conditions were ensured by sparging pure nitrogen in the culture medium for $15 \mathrm{~min}$ prior to inoculation. The cultivation conditions were $37^{\circ} \mathrm{C}$ and $300 \mathrm{rpm}$, controlled $\mathrm{pH}$ at 7.0 (using either 
$10 \mathrm{M} \mathrm{NaOH}$ or $1 \mathrm{M} \mathrm{H}_{3} \mathrm{PO}_{4}$ ). The cultivation medium for batch experiments was the same as described above, except for glycerol concentration, which was tested at two levels: 15 and $65 \mathrm{~g} \mathrm{~L}^{-1}$ using raw glycerol. The bioreactors were inoculated with an inoculum set to OD of 1.0 at $600 \mathrm{~nm}$, at a volume fraction corresponding to $10 \%$ of the cultivation volume. All experimental runs were performed in duplicates.

\section{Fed-batch cultivations}

Fed-batch experiments were performed in 5-L stirred-tank bioreactors (Biostat B model). Bioreactor assembly and culture conditions were the same as described for batch cultivations. The cultivation medium for fed-batch experiments was the same as described above, except for glycerol concentration, which was set to $15 \mathrm{~g} \mathrm{~L}^{-1}$ raw glycerol. All experimental runs were performed in duplicates.

The initial volume of culture media was either 1 or $2 \mathrm{~L}$ to ensure that the final fermentation volume would not surpass $5 \mathrm{~L}$, and the volume of inoculum was adapted accordingly. The feeding solution was either sterile raw glycerol or a complex culture medium containing raw glycerol (in order to achieve a $700 \mathrm{~g} \mathrm{~L}^{-1}$ glycerol concentration) and the remaining components of culture medium in the concentrations previously described in the "Microorganism maintenance and inoculum preparation" sub-section. Feeding was initiated $4 \mathrm{~h}$ after inoculation, which had been determined by preliminary batch experiments to be the time for complete depletion of the carbon source in the batch mode. An external peristaltic pump (Wattson-Marlow 120U/DV, USA) was employed with the aid of a communication board (Arduino Uno, Switzerland) connected to an independent computer running Arduino Software (IDE) 1.6.5, ${ }^{23}$ which controls the algorithm containing the feeding equation $1, \mathrm{~F}(\mathrm{t})\left(\mathrm{L} \mathrm{h}^{-1}\right)$ :

$\mathrm{F}(\mathrm{t})=\frac{\mu_{\mathrm{set}} \mathrm{V}_{0} \mathrm{X}_{0} \mathrm{e}^{\mu_{\mathrm{set}}}}{\mathrm{Y}_{\mathrm{x} / \mathrm{s}} \mathrm{S}_{\mathrm{F}}}$

where $\mu_{\text {set }}$ is the set-point for a specific growth rate $\left(\mathrm{h}^{-1}\right)$; $\mathrm{t}$ is the feeding time $(\mathrm{h}) ; \mathrm{V}_{0}$ is the volume of culture medium at the start of the feeding $(\mathrm{L}) ; \mathrm{X}_{0}$ is the biomass concentration at the start of the feeding $\left(\mathrm{g} \mathrm{L}^{-1}\right) ; \mathrm{Y}_{\mathrm{X} / \mathrm{S}}$ is the biomass yield $\left(\mathrm{g} \mathrm{g}^{-1}\right)$; and $\mathrm{S}_{\mathrm{F}}$ is the substrate concentration in the feeding solution $\left(\mathrm{g} \mathrm{L}^{-1}\right)$. This feeding equation is achieved through mass balance, assuming constant cell yield on substrate and residual substrate zero in the cultivation medium, and its basic theory can be found in detail in the work by Lee. ${ }^{13}$
At the start of the feeding, a quick biomass concentration analysis was carried out in order to determine the value of $\mathrm{X}_{0}$ at the time and insert it correctly into the feeding equation in the algorithm. This analytical method is described in the "Analytical methods" sub-section. Samples were taken every hour during the first $9 \mathrm{~h}$ of culture and subsequently every $3 \mathrm{~h}$ until the end of the process at $48 \mathrm{~h}$ of cultivation.

\section{Analytical methods}

The concentrations of glycerol and fermentation metabolites in the culture medium were analyzed by highperformance liquid chromatography (HPLC; Prominence, Shimadzu, Japan) assembled with refractive index detector (RID-10A, Shimadzu). The column was Aminex HPX-87H $(300 \times 7.8 \mathrm{~mm}$, Bio-Rad, USA), and the mobile phase, a $0.005 \mathrm{~mol} \mathrm{~L}^{-1} \mathrm{H}_{2} \mathrm{SO}_{4}$ solution, was fed at $0.8 \mathrm{~mL} \mathrm{~min}{ }^{-1}$. The column temperature was controlled at $65^{\circ} \mathrm{C}$. Culture samples were centrifuged $(3,000 \times \mathrm{g}, 15 \mathrm{~min})$, and the supernatant was filtrated using cellulose acetate membranes (0.22 $\mu \mathrm{m}$ pore size; Sartorius, Germany). For all HPLC analyses, standards of HPLC grade of glycerol, 1,3-PDO, 2,3-BDO, ethanol, acetic acid, and lactic acid were used (>99.5\% purity).

The biomass concentration was determined by dry cell weight at $65{ }^{\circ} \mathrm{C}$. For immediate acquisition of the value of biomass concentration at the start of the glycerol feeding $(\mathrm{t}=4 \mathrm{~h})$, a quick gravimetric method was used in order to input this information $\left(\mathrm{X}_{0}\right)$ correctly into the feeding equation. The samples were centrifuged $(3,000 \times \mathrm{g}$, $15 \mathrm{~min}$ ), and then the biomass was spread onto a paper filter (Whatman 1001-090, United Kingdom) that was dried in a moisture analyzer (Ohaus MB-35, Germany) and its weight determined using an analytical scale (Ohaus 25.1, USA). All analyses were performed in duplicates.

The statistics of experimental data were analyzed by Tukey's test using software Statistica $10^{24}$ at a significance level of 0.05 .

\section{Results and Discussion}

Preliminary batch cultivation experiments using 65 and $15 \mathrm{~g} \mathrm{~L}^{-1}$ of raw glycerol concentration were performed to determine the ideal condition that would be used to run the fed-batch experiments. The objective was to determine the shortest initial batch time, while obtaining enough biomass concentration and low inhibitory products for fed-batch cultivation to start (Table 1). From results in Table 1, an initial concentration of $15 \mathrm{~g} \mathrm{~L}^{-1}$ of raw glycerol was chosen and the parameters required for the fed-batch 
cultivation, i.e., the maximum growth rate $\left(\mu_{\max }\right)$ and the conversion of glycerol to biomass $\left(\mathrm{Y}_{\mathrm{X} / \mathrm{S}}\right)$ were determined through linear regression of experimental data. Kinetic batch cultivations of glycerol consumption and biomass formation (logarithmic scale) were obtained (Figures 1 and 2), and data was used to determine the experimental values of $\mu_{\max }\left(0.35 \mathrm{~h}^{-1}\right)$ and $\mathrm{Y}_{\mathrm{X} / \mathrm{S}}\left(0.13 \mathrm{~g} \mathrm{~g}^{-1}\right)$ using linear regression analysis.

Table 1. Specific growth rates and yields obtained in batch cultivations of $K$. pneumoniae BLh-1 under anaerobic conditions

\begin{tabular}{lccc}
\hline $\begin{array}{l}\text { Glycerol } \\
\text { concentration } / \\
\left(\mathrm{g} \mathrm{L}^{-1}\right)\end{array}$ & $\mu_{\max } / \mathrm{h}^{-1}$ & $\mathrm{Y}_{\mathrm{X} / \mathrm{s}^{\mathrm{a}}} /\left(\mathrm{g} \mathrm{g}^{-1}\right)$ & $\mathrm{Y}_{1,3-\mathrm{PDO}^{\mathrm{a}}} /\left(\mathrm{g} \mathrm{g}^{-1}\right)$ \\
\hline 65 & 0.35 & $0.073^{\mathrm{A}}$ & $0.38^{\mathrm{A}}$ \\
15 & 0.35 & $0.13^{\mathrm{B}}$ & $0.51^{\mathrm{B}}$ \\
\hline
\end{tabular}

${ }^{a}$ Different letters in the same column mean statistic difference by Tukey's test at significance level of 5\%. $\mu_{\max }$ : maximum growth rate; $\mathrm{Y}_{\mathrm{X} / \mathrm{S}}$ : conversion of glycerol to biomass; $\mathrm{Y}_{1,3-\mathrm{PDO}}$ : conversion of glycerol to $1,3-\mathrm{PDO}$.

Fed-batch experiments were carried out using three different values of specific growth rates $\left(\mu_{\text {set }}\right)$ set for the exponential feed profiles: $0.035,0.070$, and $0.105 \mathrm{~h}^{-1}$ (Figures 3-5). The time courses of 1,3-PDO and ethanol productivities are shown in Figure 6. Productions of 1,3-PDO and ethanol were observed in all levels of specific growth rates that were tested. Increased 1,3-PDO yields were observed in all fed-batch tests compared to batch experiments. 2,3-BDO formation was absent from all cultivations.

It was possible to conduct fed-batch cultivation maintaining low residual glycerol concentrations over a long period in experiments of $\mu_{\max } 0.035 \mathrm{~h}^{-1}$ (accumulation occurring only after $36 \mathrm{~h}$ ) (Figure 3 ). The formation of 1,3-PDO increased continuously, reaching $30.3 \mathrm{~g} \mathrm{~L}^{-1}$ at the end of $48 \mathrm{~h}$, suggesting that the continuity of the feeding could lead to higher concentrations of 1,3-PDO, although the reduction in productivity towards the end of the process suggests the impending stagnation in its production (Figure 6). Similar behavior was observed for the formation of ethanol, the production of which ceased after about $42 \mathrm{~h}$, reaching $11.7 \mathrm{~g} \mathrm{~L}^{-1}$. The acetic acid concentration increased drastically after $24 \mathrm{~h}$ of culture, and final concentrations of acetic and lactic acids were 17.3 and $7.8 \mathrm{~g} \mathrm{~L}^{-1}$, respectively. Increasing values of yields were observed for 1,3-PDO and ethanol over time, reaching final values of 0.58 and $0.22 \mathrm{~g} \mathrm{~g}^{-1}$, respectively. The productivity for these metabolites varied over time, with maximum values of $1.56 \mathrm{~g} \mathrm{~L}^{-1} \mathrm{~h}^{-1}$ of 1,3-PDO and $0.54 \mathrm{~g} \mathrm{~L}^{-1} \mathrm{~h}^{-1}$ of ethanol, which were both observed at $5 \mathrm{~h}$ of fermentation.
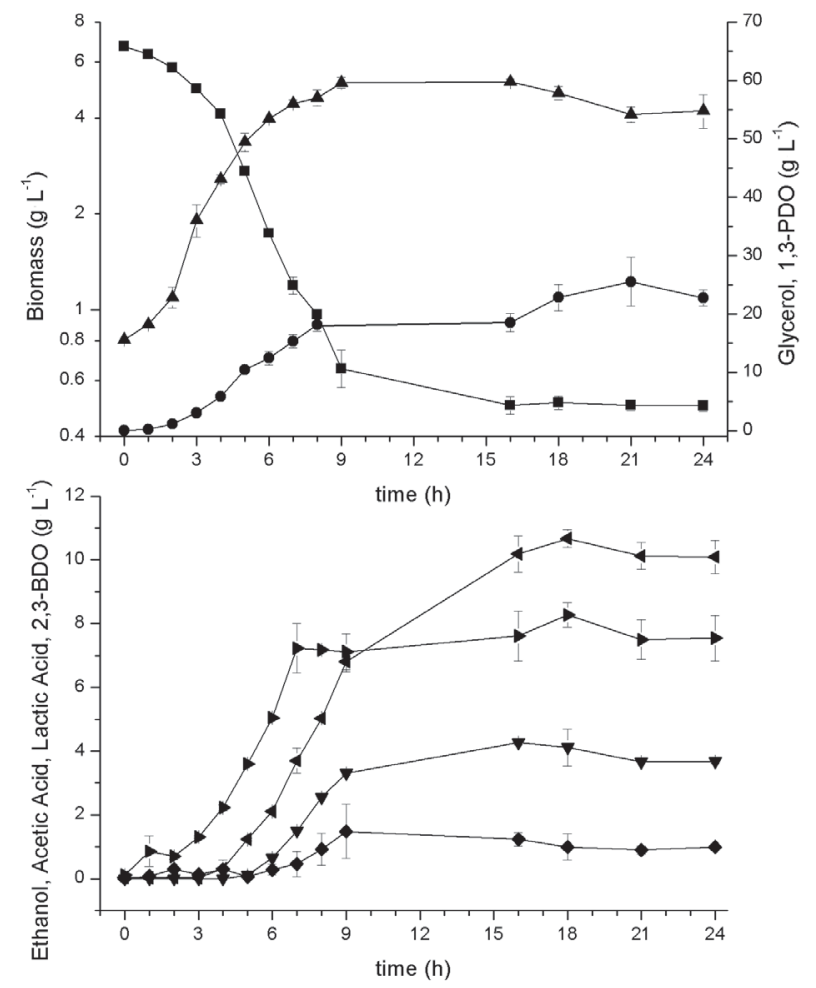

Figure 1. Batch cultivation of $K$. pneumoniae BLh-1 in bioreactor under

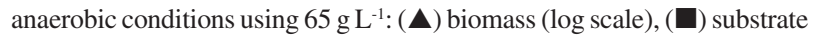
(glycerol), (\) 1,3-PDO, ( ) lactic acid, (\) acetic acid, ( ) ethanol, and $(\boldsymbol{\nabla})$ 2,3-BDO. Results are the mean of duplicates.
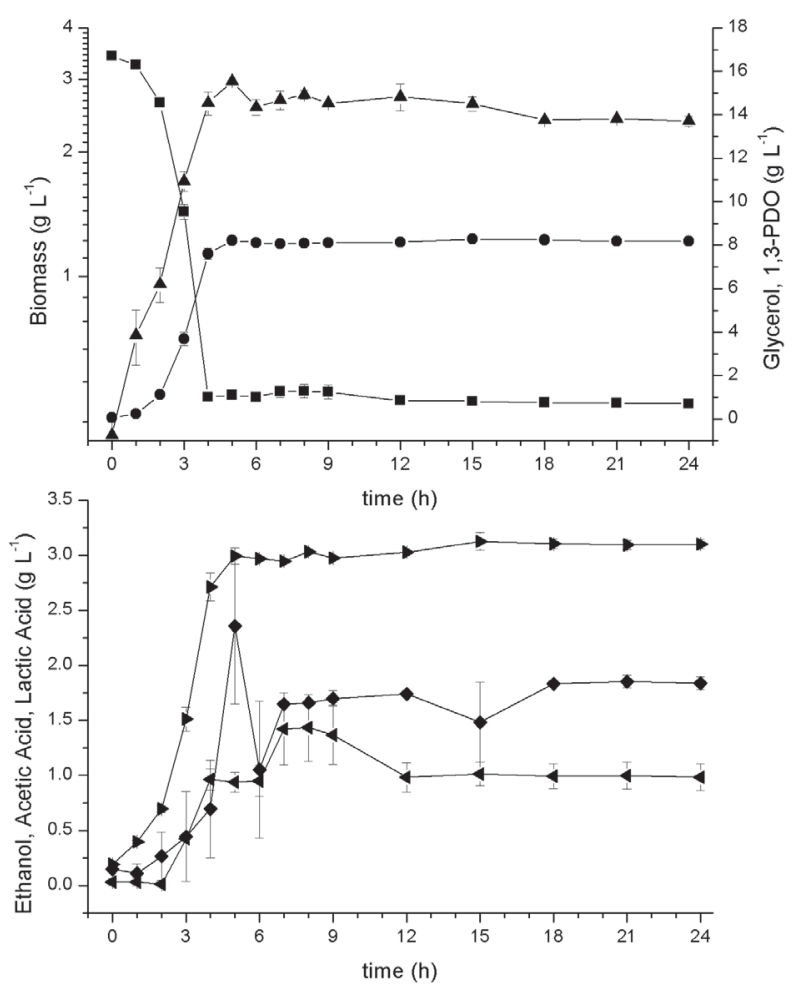

Figure 2. Batch cultivation of $K$. pneumoniae BLh-1 in bioreactor under anaerobic conditions using $15 \mathrm{~g} \mathrm{~L}^{-1}:(\mathbf{\Lambda})$ biomass (log scale), ( $\left.\mathbf{\square}\right)$ substrate (glycerol), ( ) 1,3-PDO, ( ) lactic acid, (\) acetic acid, and ( ) ethanol. Results are the mean of duplicates. 


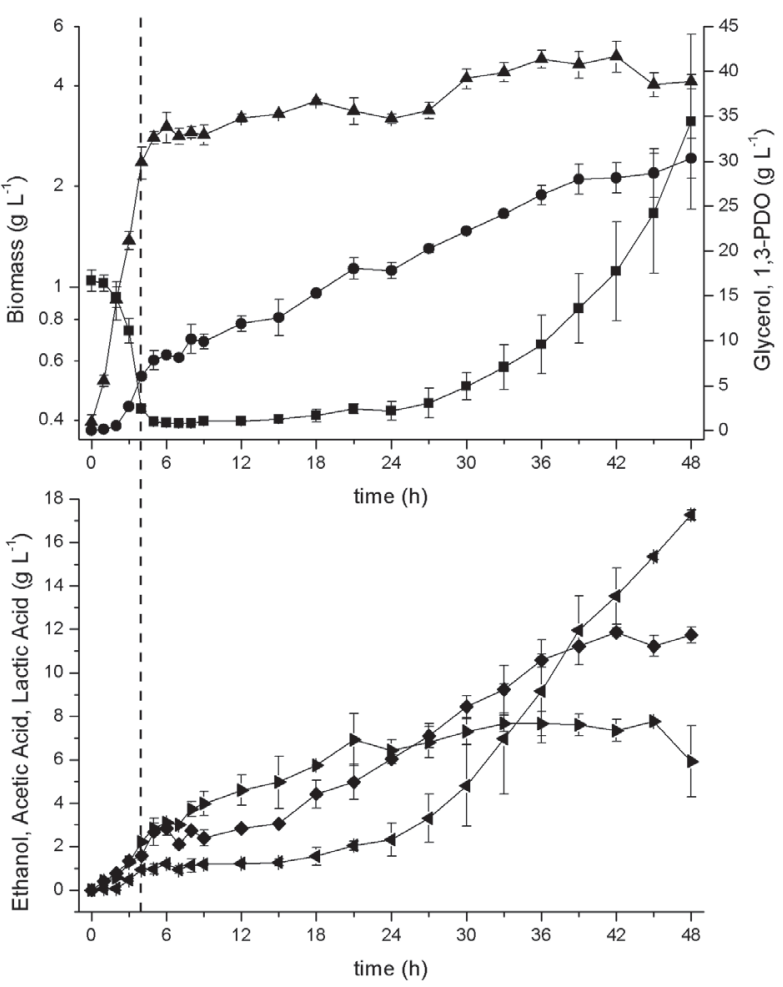

Figure 3. Fed-batch cultivation of $K$. pneumoniae BLh-1 in bioreactor under anaerobic conditions using $\mu_{\text {set }} 0.035 \mathrm{~h}^{-1}$ : (ム) biomass (log scale),

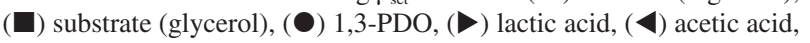
and $(\checkmark)$ ethanol. Feeding medium raw glycerol; dashed line indicates the start of feeding. Results are the mean of duplicates.

Overall productivities for 1,3-PDO and ethanol were 0.63 and $0.24 \mathrm{~g} \mathrm{~L}^{-1} \mathrm{~h}^{-1}$, respectively (Table 2).

When a $\mu_{\max }$ value of $0.070 \mathrm{~h}^{-1}$ was tested, it was possible to maintain residual concentrations of glycerol under $10 \mathrm{~g} \mathrm{~L}^{-1}$ for $21 \mathrm{~h}$; thereafter, a sharp build-up was observed (Figure 2), and a final concentration of 1,3-PDO of $35.04 \mathrm{~g} \mathrm{~L}^{-1}$ was achieved at the end of $33 \mathrm{~h}$. Ethanol productivity fell sharply after $27 \mathrm{~h}$, and a final concentration of $14.4 \mathrm{~g} \mathrm{~L}^{-1}$ was achieved. Glycerol accumulated after $18 \mathrm{~h}$, concomitantly with the increase of acetic acid concentration. In a similar way to the previously described yields, increasing values were found for 1,3-PDO and ethanol over time, reaching final values of 0.54 and $0.22 \mathrm{~g} \mathrm{~g}^{-1}$, respectively. Productivity values for these products varied over time; highest values of 1,3-PDO $\left(1.74 \mathrm{~g} \mathrm{~L}^{-1} \mathrm{~h}^{-1}\right)$ and ethanol $\left(0.54 \mathrm{~g} \mathrm{~L}^{-1} \mathrm{~h}^{-1}\right)$ were observed at 4 and $5 \mathrm{~h}$ of fermentation, respectively. The overall productivities were 1.06 and $0.44 \mathrm{~g} \mathrm{~L}^{-1} \mathrm{~h}^{-1}$ for 1,3-PDO and ethanol, respectively (Table 2).

Finally, in experiments under a $\mu_{\max }$ value of $0.105 \mathrm{~h}^{-1}$, residual glycerol concentrations were kept below $10 \mathrm{~g} \mathrm{~L}^{-1}$ for $18 \mathrm{~h}$, and they exhibited marked accumulation after this time (Figure 5). Glycerol metabolism decreased sharply, and a distinct dilution effect by non-metabolized substrate

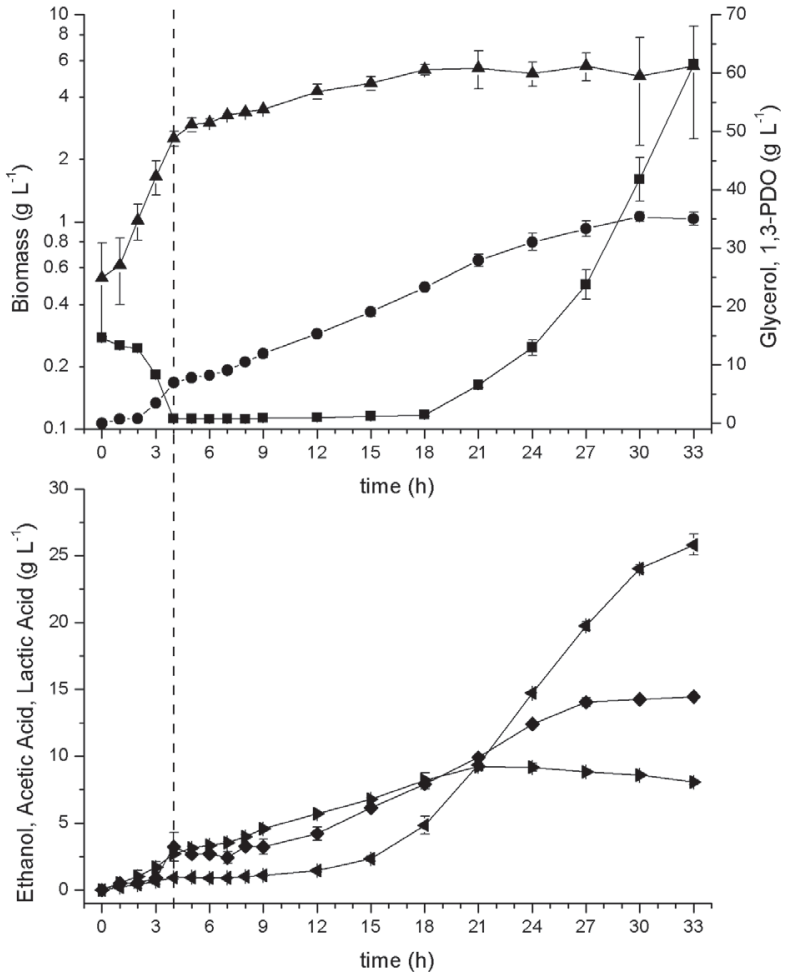

Figure 4. Fed-batch cultivation of K. pneumoniae BLh-1 in bioreactor

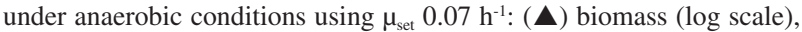

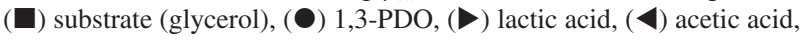
and ( ) ethanol. Feeding medium raw glycerol; dashed line indicates the start of feeding. Results are the mean of duplicates.

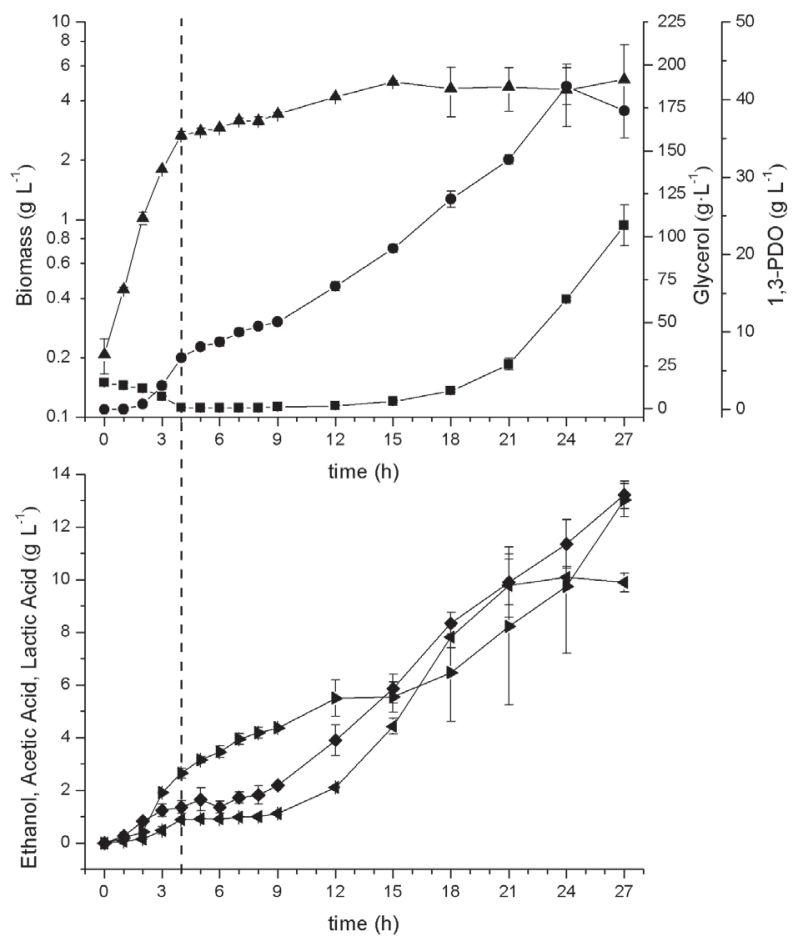

Figure 5. Fed-batch cultivation of $K$. pneumoniae BLh-1 in bioreactor under anaerobic conditions using $\mu_{\mathrm{set}} 0.105 \mathrm{~h}^{-1}$ : ( $\left.\mathbf{\Delta}\right)$ biomass (log scale),

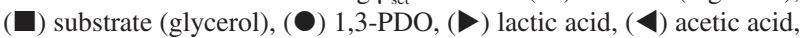
and $(\bullet)$ ethanol. Feeding medium raw glycerol; dashed line indicates the start of feeding. Results are the mean of duplicates. 


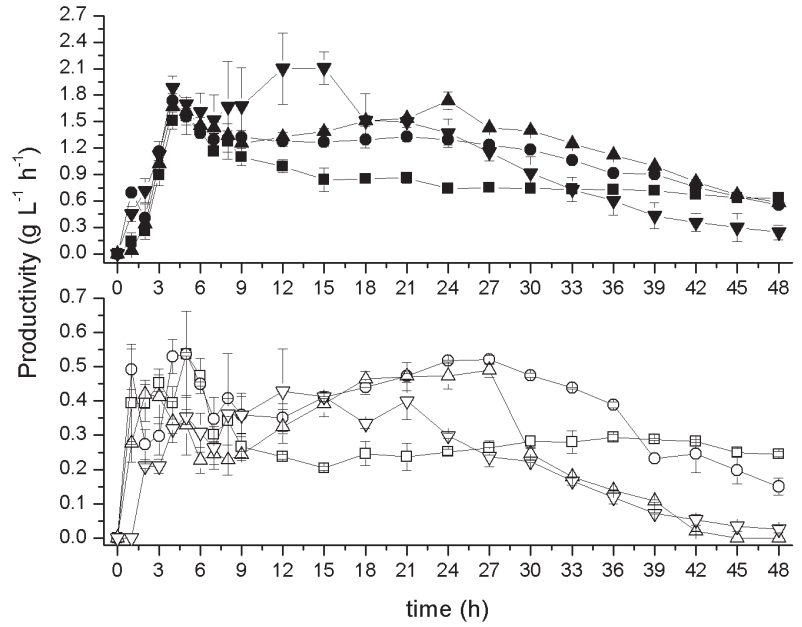

Figure 6. (a) 1,3-PDO and (b) ethanol productivities at different levels of $\mu_{\text {set }}$. 1,3-PDO: $(\square) 0.035 \mathrm{~h}^{-1},(\bullet) 0.07 \mathrm{~h}^{-1},(\boldsymbol{\Delta}) 0.105 \mathrm{~h}^{-1},(\boldsymbol{\nabla}) 0.105 \mathrm{~h}^{-1}$ and feeding with complex medium; ethanol: $(\square) 0.035 \mathrm{~h}^{-1}$, (○) $0.07 \mathrm{~h}^{-1}$, $(\diamond) 0.105 \mathrm{~h}^{-1},(\nabla) 0.105 \mathrm{~h}^{-1}$ and feeding with complex medium. Feeding medium raw glycerol. Results are the mean of duplicates.

was observed after $27 \mathrm{~h}$, leading to low concentrations of metabolites. 1,3-PDO reached a maximum concentration of $38.5 \mathrm{~g} \mathrm{~L}^{-1}$ and then stagnated after $24 \mathrm{~h}$. Ethanol production reached the maximum concentration of $13.2 \mathrm{~g} \mathrm{~L}^{-1}$ after $27 \mathrm{~h}$. There was high glycerol accumulation after $18 \mathrm{~h}$. Increasing values of 1,3-PDO and ethanol yields were observed over time, reaching final values of 0.56 and $0.19 \mathrm{~g} \mathrm{~g}^{-1}$, respectively. Productivities of these products varied over time, reaching maximum values of $1.74 \mathrm{~g} \mathrm{~L}^{-1} \mathrm{~h}^{-1}$ of $1,3-\mathrm{PDO}$ and $0.49 \mathrm{~g} \mathrm{~L}^{-1} \mathrm{~h}^{-1}$ of ethanol, which were observed at 24 and $27 \mathrm{~h}$, respectively (Table 2).

The final concentration of 1,3-PDO and the yields of 1,3-PDO and ethanol ( $\mathrm{Y}_{1,3-\mathrm{PDO}}$ and $\mathrm{Y}_{\text {ethanol }}$, respectively) showed no statistical difference among the different specific growth rates (Table 2). The final concentrations of ethanol and lactic acid, however, were affected by the specific growth rate: 0.070 and $0.105 \mathrm{~h}^{-1}$ led to higher concentrations, and there were no statistically significant differences between them. The final concentration of acetic acid differed statistically at all levels tested. The specific growth rate value for which there was a higher final concentration of this metabolite was $0.070 \mathrm{~h}^{-1}$, and $0.105 \mathrm{~h}^{-1}$ produced the lowest concentration. More importantly, the productivity of 1,3-PDO $\left(\mathrm{Q}_{1,3-\mathrm{PDO}}\right)$ was also affected by $\mu_{\mathrm{set}}$, and a clear pattern was observed: higher values of $\mu_{\text {set }}$ led to higher productivity. Ethanol productivity $\left(\mathrm{Q}_{\text {ethanol }}\right)$ showed higher values when $\mu_{\text {set }}$ values of 0.07 and $0.105 \mathrm{~h}^{-1}$ were tested, but there were no statistically significant differences.

In order to assess the hypothesis that cell growth arrest towards the end of fermentation could be related to the depletion of other components of the culture medium, a fed-batch cultivation was carried out (in duplicates) at the level of specific growth rate determined to have led to best results $\left(0.105 \mathrm{~h}^{-1}\right)$. For these experiments, the addition of raw glycerol as a feed solution was exchanged by a complex culture medium containing raw glycerol and the remaining components of culture medium ("Fed-batch cultivation" sub-section). The volumetric productivities are shown in Figure 6, and the time courses of metabolites are shown in Figure 7. Experimental results are also summarized in Table 2. As can be seen in these Figures and Table 1, the use of a complete medium for feeding at a $\mu_{\text {set }}$ value of $0.105 \mathrm{~h}^{-1}$ did not improve results observed for raw glycerol feeding. Residual glycerol concentrations were kept below $10 \mathrm{~g} \mathrm{~L}^{-1}$ for $18 \mathrm{~h}$, and accumulation occurred thereafter. Final concentrations of 1,3-PDO and ethanol were 31.1 and $6.4 \mathrm{~g} \mathrm{~L}^{-1}$, respectively, which were lower concentrations compared to those achieved when feeding raw glycerol. Biomass formation, however, was higher, reaching a final concentration of $8.3 \mathrm{~g} \mathrm{~L}^{-1}$. 1,3-PDO and ethanol yields were 0.23 and $0.05 \mathrm{~g} \mathrm{~g}^{-1}$, respectively. Both were considerably lower than those obtained when feeding raw glycerol. Productivity for these metabolites varied over time with maximum values of $2.11 \mathrm{~g} \mathrm{~L}^{-1} \mathrm{~h}^{-1}$ for 1,3-PDO and $0.43 \mathrm{~g} \mathrm{~L}^{-1} \mathrm{~h}^{-1}$ for ethanol, which were observed at 15 and $12 \mathrm{~h}$, respectively. Final productivities were $1.15 \mathrm{~g} \mathrm{~L}^{-1} \mathrm{~h}^{-1}$ for 1,3-PDO and $0.24 \mathrm{~g} \mathrm{~L}^{-1} \mathrm{~h}^{-1}$ for ethanol.

The global analysis of experimental results indicates that the use of a specific growth rate $\left(\mu_{\text {set }}\right)$ of $0.105 \mathrm{~h}^{-1}$

Table 2. Concentrations of metabolites (C), yields (Y), and productivities (Q) obtained in fed-batch cultivations of K. pneumoniae BLh-1 under anaerobic conditions. Cultures fed either using raw glycerol or complex culture medium containing raw glycerol

\begin{tabular}{|c|c|c|c|c|c|c|c|c|c|c|c|c|}
\hline$\mu_{\text {set }}{ }^{a} / h^{-1}$ & Feed solution & $\begin{array}{c}\text { Evaluation } \\
\text { time / h }\end{array}$ & $\begin{array}{c}\text { Initial } \\
\text { volume / L }\end{array}$ & $\begin{array}{l}\text { Final volume } \\
(\mathrm{t}=48 \mathrm{~h}) / \mathrm{L}\end{array}$ & $\begin{array}{c}\mathrm{C}_{1,3-\mathrm{PDO}}^{\mathrm{b}} / \mathrm{d} \\
\left(\mathrm{g} \mathrm{L}^{-1}\right)\end{array}$ & $\begin{array}{l}\mathrm{C}_{\text {ethanol }}^{\mathrm{b}} / \\
\left(\mathrm{g} \mathrm{L}^{-1}\right)\end{array}$ & $\begin{array}{l}\mathrm{C}_{\text {acet }}{ }^{\mathrm{b}} / \\
\left(\mathrm{g} \mathrm{L}^{-1}\right)\end{array}$ & $\begin{array}{l}\mathrm{C}_{\mathrm{lac}}^{\mathrm{b}} / \\
\left(\mathrm{g} \mathrm{L}^{-1}\right)\end{array}$ & $\begin{array}{c}\mathrm{Y}_{1,3-\mathrm{PDO}}^{\mathrm{c}} / \\
\left(\mathrm{g} \mathrm{g}^{-1}\right)\end{array}$ & $\begin{array}{c}\mathrm{Y}_{\text {ethanol }} \mathrm{c} / \\
\left(\mathrm{g} \mathrm{g}^{-1}\right)\end{array}$ & $\begin{array}{l}\mathrm{Q}_{1,3-\mathrm{PDO}}^{\mathrm{d}} / \\
\left(\mathrm{g} \mathrm{L}^{-1} \mathrm{~h}^{-1}\right)\end{array}$ & $\begin{array}{l}\mathrm{Q}_{\text {ethanol }}^{\mathrm{d}} / \\
\left(\mathrm{g} \mathrm{L}^{-1} \mathrm{~h}^{-1}\right)\end{array}$ \\
\hline 0.035 & raw glycerol & 48 & 2 & 2.14 & $30.3 \pm 2.2^{\mathrm{A}}$ & $11.7 \pm 0.4^{\mathrm{B}}$ & $17.3 \pm 0.2^{\mathrm{B}}$ & $5.9 \pm 1.6^{\mathrm{B}}$ & $0.58 \pm 0.0^{\mathrm{A}}$ & $0.22 \pm 0.0^{\mathrm{A}}$ & $0.63 \pm 0.0^{\mathrm{C}}$ & $0.24 \pm 0.0^{\mathrm{B}}$ \\
\hline 0.070 & raw glycerol & 33 & 2 & 2.77 & $35.0 \pm 1.1^{\mathrm{A}}$ & $14.4 \pm 0.1^{\mathrm{A}}$ & $25.8 \pm 0.8^{\mathrm{A}}$ & $8.1 \pm 0.2^{\mathrm{AB}}$ & $0.54 \pm 0.0^{\mathrm{A}}$ & $0.22 \pm 0.0^{\mathrm{A}}$ & $1.06 \pm 0.0^{\mathrm{B}}$ & $0.44 \pm 0.0^{\mathrm{A}}$ \\
\hline 0.105 & raw glycerol & 27 & 1 & 2.86 & $38.5 \pm 0.4^{\mathrm{A}}$ & $13.2 \pm 0.5^{\mathrm{AB}}$ & $9.9 \pm 0.4^{\mathrm{C}}$ & $13.0 \pm 0.6^{\mathrm{A}}$ & $0.56 \pm 0.1^{\mathrm{A}}$ & $0.19 \pm 0.0^{\mathrm{A}}$ & $1.43 \pm 0.0^{\mathrm{A}}$ & $0.49 \pm 0.0^{\mathrm{A}}$ \\
\hline 0.105 & $\begin{array}{l}\text { complex culture } \\
\text { medium }\end{array}$ & 27 & 1 & 3.76 & $31.1 \pm 2.6$ & $6.4 \pm 0.7$ & $15.2 \pm 0.8$ & $5.0 \pm 1.7$ & $0.23 \pm 0.0$ & $0.05 \pm 0.0$ & $1.15 \pm 0.1$ & $0.24 \pm 0.0$ \\
\hline
\end{tabular}

${ }^{\mathrm{a}} \mu_{\mathrm{set}}$ : growth rate set-point; ${ }^{\mathrm{b}} \mathrm{C}_{1,3-\mathrm{PDO}}, \mathrm{C}_{\text {ethanol }}, \mathrm{C}_{\text {acee }}, \mathrm{C}_{\mathrm{lac}}$ : concentration of 1,3-propanediol, ethanol, acetic acid and lactic acid, respectively; ${ }^{\mathrm{C}} \mathrm{Y}$ : yield; ${ }^{\mathrm{d}} \mathrm{Q}$ : productivity. $\mathrm{A}, \mathrm{B}, \mathrm{C}$ Different letters in the same column mean statistic difference by Tukey's test at significance level of $5 \%$. 


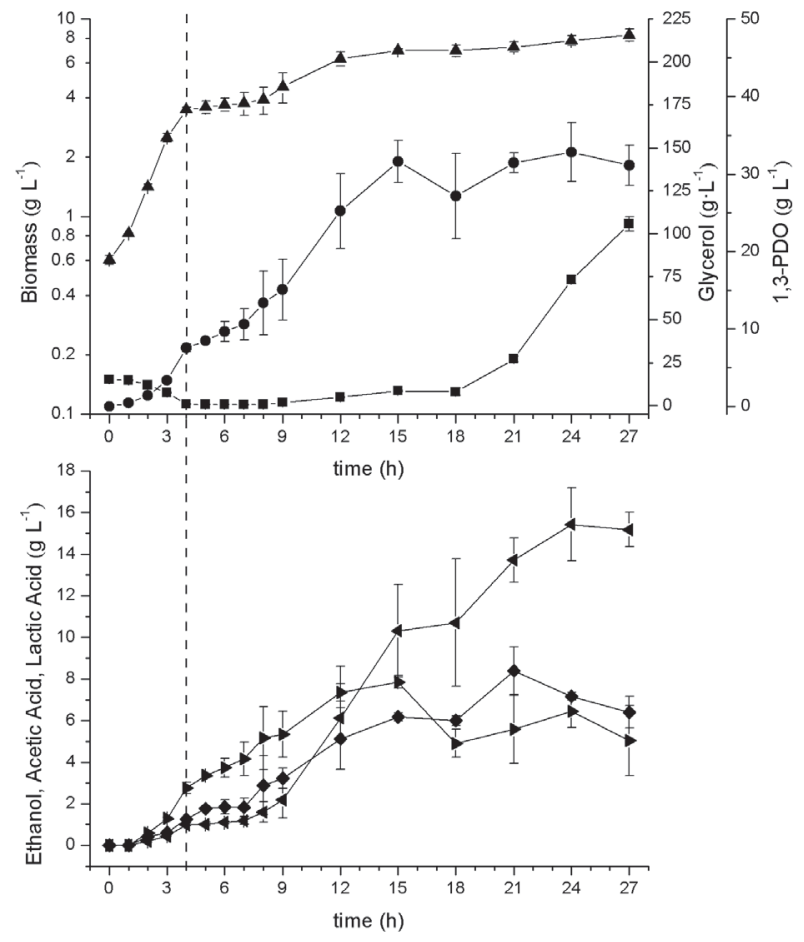

Figure 7. Fed-batch cultivation of $K$. pneumoniae BLh-1 in bioreactor under anaerobic conditions using $\mu_{\text {set }} 0.105 \mathrm{~h}^{-1}$ using complex culture medium as feeding solution: $(\boldsymbol{\Delta})$ biomass (log scale), ( $\boldsymbol{\square})$ substrate (glycerol), ( 1,3-PDO, ( ) lactic acid, (\) acetic acid, and $(\bullet)$ ethanol. Dashed line indicates the start of feeding. Results are the mean of duplicates.

produced the best results using fed-batch operation with an exponential feeding profile. Throughout the period of automatic feeding, 1,3-PDO yields not lower than $0.41 \mathrm{~g} \mathrm{~g}^{-1}$ were observed. Such high yields suggest that the metabolic pathway of K. pneumoniae BLh-1 was shifted towards the production of this metabolite. The highest values of 1,3-PDO and ethanol productivities were observed during the period of 4 to $24 \mathrm{~h}$ of fermentation (as presented in Figure 6), which corresponds to the initial phase of substrate feeding when the mass flow of raw glycerol ranged between its lowest values. During this period, the residual concentration of glycerol in the medium was maintained between 6.7 and $41.7 \mathrm{~g} \mathrm{~L}^{-1}$. Similarly, in cultures using specific growth rates of 0.035 and $0.070 \mathrm{~h}^{-1}$, the highest values observed for productivity correspond to the period in which the residual glycerol concentration in the culture medium remained relatively low. The calculated yields of 1,3-PDO reached approximately $94.4 \%$ relative to the theoretical conversion rate of $0.72 \mathrm{~mol} \mathrm{~mol}^{-1}$ when $\mu_{\text {set }}$ was set to $0.105 \mathrm{~h}^{-1} .^{25}$ The high formation of acetic acid and lactic acid suggests the possibility of inhibition due to the accumulation of these metabolites in the culture medium.

The metabolic pathway of glycerol bioconversion is a coupled oxidation-reduction process, and has been elegantly reviewed by Kaur et al. ${ }^{10}$ Generation of energy in the form of adenosine triphosphate (ATP) and reducing equivalents in the form of reduced nicotinamide adenine dinucleotide (NADH) $+\mathrm{H}^{+}$occurs in the oxidative branch, while regeneration of oxidized NAD $\left(\mathrm{NAD}^{+}\right)$concomitant with the formation of reduced product 1,3-PDO occurs in the reductive branch. $\mathrm{NADH}+\mathrm{H}^{+}$is generated during glycolytic reactions (oxidative branch), which also yield several other by-products.

Since the operating conditions used indicate specificity in the metabolic pathway of the microorganism to produce 1,3-PDO, the fed-batch strategy employed was considered efficient. 1,3-PDO yields and productivities obtained in this study were similar to other reports in the literature. The production of 1,3-PDO in fed-batch cultures was reviewed by Kaur et al., ${ }^{10}$ and results obtained by some important works are shown in Table 3. Most of the works compared in Table 2 made use of either continuous or pulsed feeding of substrate linked to $\mathrm{pH}$ control, $\mathrm{CO}_{2}$ consumption, or other process variables. The use of an exponential feeding profile $\mathrm{F}(\mathrm{t})$, as used in this work, is therefore a novel approach on the conversion of glycerol into metabolites by $K$. pneumoniae.

Improvement was achieved in the production of 1,3-PDO when comparing the results obtained in this study with those obtained by Rossi et al. ${ }^{7}$ using the same strain, $K$. pneumoniae BLh-1, under anaerobiosis in fed-batch cultivations with constant flow rates. By employing a constant feed flow, the authors reported highest concentrations of $26.1 \mathrm{~g} \mathrm{~L}^{-1} 1,3-\mathrm{PDO}$ (feeding rate of $10.0 \mathrm{~g} \mathrm{~h}^{-1}$, cultivation time of $32 \mathrm{~h}$ ), 1,3-PDO yields of $0.40 \mathrm{~g} \mathrm{~g}^{-1}\left(5 \mathrm{~g} \mathrm{~h}^{-1}\right.$ at $\left.9 \mathrm{~h}\right)$, and productivity of $2.26 \mathrm{~g} \mathrm{~L}^{-1} \mathrm{~h}^{-1}$ $\left(2.5 \mathrm{~g} \mathrm{~h}^{-1}, 9 \mathrm{~h}\right)$. It is important to note that the results reported by Rossi et al. ${ }^{7}$ indicated a sharp decrease in yields and productivities with fermentation time, suggesting that the application of constant feed flow rates are not adequate to the studied process.

Works in which higher final concentrations of 1,3-PDO were obtained had longer process times and could avoid the accumulation of glycerol in the culture medium. It is suggested that the aforementioned specificity in the shift of the metabolic pathway towards 1,3-PDO formation is strongly connected to the maintenance of substrate supply within a specified range of concentration throughout the process, which is corroborated by results in the available literature. Therefore, techniques capable of measuring or inferring the substrate concentration in the culture medium along time, thus controlling the substrate feed, might produce better results.

Continuous cultivations were performed using K. pneumoniae DSM 2026 at different dilution rates 
Table 3. Different fed-batch culture strategies for 1,3-PDO production described in the literature and their comparison with results obtained in this work

\begin{tabular}{|c|c|c|c|c|c|c|}
\hline Strain & Substrate & Feeding strategy & $\begin{array}{l}\mathrm{C}_{1,3-\text {-PDO }} / \\
\left(\mathrm{g} \mathrm{L}^{-1}\right) \\
\end{array}$ & $\begin{array}{c}\mathrm{Y}_{1,3-\mathrm{PDO}} / \\
\left(\mathrm{g} \mathrm{g}^{-1}\right)\end{array}$ & $\begin{array}{l}\mathrm{Q}_{1,3-\mathrm{PDO}} / \\
\left(\mathrm{g} \mathrm{L}^{-1} \mathrm{~h}^{-1}\right) \\
\end{array}$ & Reference \\
\hline C. butyricum VPI3266 & glycerol & linked to $\mathrm{CO}_{2}$ production & 65 & 0.57 & 1.21 & 14 \\
\hline C. butyricum DSM5431 & glycerol & $\begin{array}{c}\text { coupled feeding of glycerol } \\
\text { and ammonium linked to alkali } \\
\text { consumption }\end{array}$ & 70.4 & 0.56 & 1.4 & 15 \\
\hline C. butyricum mutant $2 / 2$ & glycerol & $\begin{array}{l}\text { coupled feeding of glycerol } \\
\text { and ammonium linked to alkali } \\
\text { consumption }\end{array}$ & 70.5 & 0.54 & 0.9 & 15 \\
\hline C. butyricum IK124 & glycerol & $\begin{array}{c}\text { low base-driven glycerol addition } \\
\text { with constant online glycerol } \\
\text { measurement }\end{array}$ & 87.0 & 0.54 & 1.9 & 16 \\
\hline C. butyricum IK124 & raw glycerol/PNC & $\begin{array}{c}\text { low base-driven glycerol addition } \\
\text { with constant online glycerol } \\
\text { measurement }\end{array}$ & 77.5 & 0.55 & 1.2 & 16 \\
\hline C. butyricum AKR102a & raw glycerol & linked to alkali consumption & 76.2 & 0.51 & 2.3 & 17 \\
\hline C. butyricum VPI1718 & raw glycerol & pulsed feed, non-sterile conditions & 67.9 & 0.55 & 0.78 & 18 \\
\hline K. pneumoniae ME-308 & glycerol & $\begin{array}{l}\text { glycerol/ammonium feed as } \mathrm{pH} \\
\text { control }\end{array}$ & 70 & 0.58 & 0.97 & 19 \\
\hline K. pneumoniae ME-303 & glycerol/corn straw & redox state-regulation & 71.6 & 0.54 & 1.93 & 20 \\
\hline K. pneumoniae DSM 4799 & raw glycerol & $\begin{array}{l}\text { feeding-flow adjusted by glycerol } \\
\text { concentration in culture medium }\end{array}$ & 71.1 & 0.55 & 1.51 & 21 \\
\hline K. pneumoniae BLh-1 & raw glycerol & constant feed of raw glycerol & 23.4 & 0.40 & 2.6 & 7 \\
\hline K. pneumoniae BLh-1 & raw glycerol & EFBC & 38.5 & 0.56 & 1.43 & this work \\
\hline
\end{tabular}

feeding glycerol (leading to steady states achieving substrate limitation or not) under anaerobiosis. ${ }^{26}$ The authors showed that under limiting substrate conditions, the production of 2,3-BDO and acetoin are insignificant compared to conditions of excess glycerol. The production of 1,3-PDO, acetate, succinate, and formate proved to be always favored in the presence of excess substrate in the culture medium. By contrast, ethanol production was higher in glycerol-limited conditions. These observations can be explained by the tendency of the organism to get rid of excess glycerol and to reduce the toxic effect caused by the accumulation of products beyond thresholds, which can occur at high dilution rates and consequent excessive glycerol concentration. ${ }^{27}$

The inhibition caused by excess of substrate and fermentation products in the growth of K. pneumoniae and the production of 1,3-PDO was studied by Cheng $\mathrm{et} \mathrm{al.}{ }^{8} \mathrm{Cell}$ growth under anaerobic conditions showed tolerance to a maximum concentration of $110 \mathrm{~g} \mathrm{~L}^{-1}$ of glycerol. Acetate was the major inhibitory metabolite during fermentation, followed by lactate and ethanol. The critical concentrations for these products were 15,19 , and $26 \mathrm{~g} \mathrm{~L}^{-1}$, respectively, whereas for 1,3-PDO, a critical concentration of $69 \mathrm{~g} \mathrm{~L}^{-1}$ was observed and thus a low inhibitory effect. The presence of $7.6 \mathrm{~g} \mathrm{~L}^{-1}$ of acetate caused a $50 \%$ reduction in cell growth, and growth was totally inhibited when the concentration of this product exceeded $15 \mathrm{~g} \mathrm{~L}^{-1}$ at a $\mathrm{pH}$ of 6.8 . Therefore, we might suggest that the formation of acetic acid and lactic acid observed in the present study led to impaired cell growth and limited formation of products of interest to some extent.

In addition to the possible inhibition caused by the formation of metabolites such as acetic and lactic acids, the depletion of other nutritional components of the culture medium throughout fermentation might have caused low metabolism for the formation of 1,3-PDO and ethanol, since the feeding solution consisted solely of raw glycerol from the biodiesel industry, and the only pre-treatment was sterilization. Information regarding the metabolic effects caused by the limitation of nitrogen and phosphate sources as well as of the variety of inorganic nutrients and trace elements known to be required for glycerol metabolism in $K$. pneumoniae is scarce in the literature. However, available knowledge on the effect of these restrictions in a variety of other organisms suggests that the possible nutritional imbalance caused by the non-replacement of these components in the culture medium throughout the fermentation process can bring harmful effects on various cell maintenance functions. ${ }^{28}$

The experiments carried out using a complex culture medium as feed solution aiming to avoid nutrient depletion showed some improvement on biomass formation. 
However, lower final titers and yields for 1,3-PDO and ethanol were observed; this phenomenon is attributed to a possible shift in metabolism towards the production of biomass caused by the different nutritional balance of a complex medium. Therefore, regarding the experimental results obtained in this work, the use of raw glycerol as a feeding solution is preferred.

\section{Conclusions}

The bacterial strain used in this work, $K$. pneumoniae BLh-1, was capable of producing 1,3-PDO efficiently using raw glycerol from the biodiesel industry as the sole carbon source under anaerobic conditions in a fed-batch system. This strain also produced ethanol, although process adaptations are necessary in order to achieve higher productions closer to titers produced by yeasts and bacteria used for ethanolic fermentation on sugar substrate. Higher yields and productivities were obtained proportionally to higher specific growth rates, and specific growth rate of $0.105 \mathrm{~h}^{-1}$ showed the best result for 1,3-PDO production. Results suggest a potential process engineering approach to further improve 1,3-PDO and ethanol production using raw glycerol by $K$. pneumoniae.

\section{Supplementary Information}

Supplementary data (model of a chromatogram of products and substrate in a typical fed-batch cultivation of K. pneumoniae BLh-1; linear regressions applied to obtain $\mathrm{Y}_{\mathrm{X} / \mathrm{S}}$ and $\mathrm{Y}_{1,3-\mathrm{PDO}}$ in Table 2) are available free of charge at http://jbcs.sbq.org.br as PDF file.

\section{Acknowledgments}

This work was partially supported by grants from the Conselho Nacional de Desenvolvimento Científico e Tecnológico (CNPq, Brazil) and Fundação de Amparo à Pesquisa do Estado do Rio Grande do Sul (FAPERGS, Brazil), and scholarships from Coordenação de Aperfeiçoamento de Pessoal de Nível Superior (CAPES, Brazil).

\section{References}

1. Ayoub, M.; Abdullah, A. Z.; Renewable Sustainable Energy Rev. 2012, 16, 2671.

2. Yazdani, S. S.; Gonzalez, R.; Metab. Eng. 2008, 10, 340.

3. Ayoub, M.; Abdullah, A. Z.; Catal. Commun. 2013, 34, 22.
4. Koutinas, A. A.; Wang, R. H.; Webb, C.; Biofuels, Bioprod. Biorefin. 2007, 1, 24.

5. Gholami, Z. Z.; Abdullah, A. Z.; Lee, K. T.; Renewable Sustainable Energy Rev. 2014, 39, 327.

6. Maervoet, V. E. T.; De Mey, M.; Beauprez, J.; De Maeseneire, S.; Soetaert, W. K.; Org. Process Res. Dev. 2011, 15, 189.

7. Rossi, D. M.; de Souza, E. A.; Ayub, M. A. Z.; Appl. Biochem. Biotechnol. 2013, 169, 1952.

8. Cheng, K.; Liu, H.; Liu, D.; Biotechnol. Lett. 2005, 17, 19.

9. Rossi, D. M.; da Costa, J. B.; de Souza, E. A.; Peralba, M. C. R.; Ayub, M. A. Z.; Renewable Energy 2012, 39, 223.

10. Kaur, G.; Srivastava, A. K.; Chand, S.; Biochem. Eng. J. 2012, $64,106$.

11. Nakamura, C. E.; Whited, G. M.; Curr. Opin. Biotechnol. 2003, $14,454$.

12. Saxena, R. K.; Anand, P.; Saran, S.; Isar, J.; Biotechnol. Adv. 2009, 27, 895 .

13. Lee, S. Y.; Trends Biotechnol. 1996, 14, 98.

14. Saint-Amans, S.; Perlot, P.; Goma, G.; Soucaille, P.; Biotechnol. Lett. 1994, 16, 831.

15. Reimann, A.; Biebl, H.; Biotechnol. Lett. 1996, 18, 827.

16. Hirschmann, S.; Baganz, K.; Koschik, I.; Vorlop, K. D.; Landbauforsch. Völkenrode 2005, 55, 261.

17. Wilkens, E.; Ringel, A. K.; Hortig, D.; Willke, T.; Vorlop, K.-D.; Appl. Microbiol. Biotechnol. 2012, 93, 1057.

18. Chatzifragkou, A.; Papanikolaou, S.; Dietz, D.; Doulgeraki, A.; Nychas, G. J.; Zeng, A. P.; Appl. Microbiol. Biotechnol. 2011, $91,101$.

19. Ji, X. J.; Huang, H.; Zhu, J. G.; Hu, N.; Li, S.; Appl. Biochem. Biotechnol. 2009, 159, 605.

20. Jin, P.; Li, S.; Lu, S.; Zhu, J.; Huang, H.; Bioresour. Technol. 2011, 102, 1815.

21. Jun, S. A.; Moon, C.; Kang, C. H.; Kong, S. W.; Sang, B. I.; Um, Y.; Appl. Biochem. Biotechnol. 2010, 161, 491.

22. Kim, B. S.; Lee, S. C.; Lee, S. Y.; Chang, Y. K.; Chang, H. N.; Bioprocess Biosyst. Eng. 2004, $26,147$.

23. h t t p s : / / w w w. a r d u in o. c c/en/M a i n / OldSoftwareReleases\#previous, accessed in May 2018.

24. StatSoft Inc.; Statistica, version 10; StatSoft Inc., Tulsa, OK, USA, 2011.

25. Zeng, A. P.; Bioprocess Eng. 1996, 14, 169.

26. Homann, T.; Tag, C.; Biebl, H.; Deckwer, W. D.; Schink, B.; Appl. Microbiol. Biotechnol. 1990, 33, 121.

27. Zeng, A. P.; Biebl, H.; Schlieker, H.; Deckwer, W.-D.; Enzyme Microb. Technol. 1993, 15, 770.

28. Harder, W.; Dijkhuizen, L.; Annu. Rev. Microbiol. 1983, 37, 1.

Submitted: March 16, 2018

Published online: May 29, 2018 